\title{
Growth Rates, Growth Models and Future Projections of Sorghum in Telangana State
}

\author{
R. Srinivas* and D. Srinivasa Chary
}

Department of Statistics \& Mathematics, College of Agriculture, Professor Jayashankar Telangana State Agricultural University, Rajendranagar, Hyderabad, India

*Corresponding author

\section{A B S T R A C T}

\section{Keywords}

Sorghum, Linear and compound growth rates

Article Info

Accepted:

16 November 2020

Available Online:

10 December 2020

\begin{abstract}
Attempts have been made to examine the trends and forecasting in area, production and productivity of Sorghum crop in Telangana State. Linear and compound growth rates were calculated for this purpose. Ten growth models were fitted to the area, production and productivity of Sorghum crop and bestfitted model for future projection was chosen based upon least Residual Mean Square (RMS) and significant $\mathrm{Adj}^{R^{2}}$ - Besides, the important assumption of randomness of residuals was tested using one sample run test. The reference period of study was from $1979-80$ to 2015-16and it was carried outin Telangana State.
\end{abstract}

\section{Introduction}

Sorghum [Sorghum bicolor (L.)] is one of the main staple food for the world's poorest and most food insecure people across the semiarid tropics. Globally, sorghum is cultivated on 41million hectares to produce 64.20 million tonnes, with productivity hovering around1.60 tonnes per hectare. With exceptions in some regions, it is mainly produced and consumed by poor farmers. India contributes about $16 \%$ of the world's sorghum production.

On global front, sorghum was grown in 105 countries of the world in the year 2010-11 covering an area of approximately $40.5 \mathrm{~m}$ ha with grain production of $55.65 \mathrm{~m}$ tons and an average productivity of 1.374 tons per ha (FAO website: http://www.fao.org). During the last three decades period (1980-2010), cropped area and production reported an annual growth rate of $-0.34 \%$ and $-0.51 \%$ respectively.

Development and adoption of the improved cultivars, improved management practices have increased the productivity levels significantly despite tumbling acreage of sorghum across the globe in recent past. Sorghum primarily produced in India $(7.38 \mathrm{~m}$ ha) constitutes about $18.21 \%$ share in global area followed by Sudan $5.61 \mathrm{~m}$ ha $(13.85 \%)$, Nigeria $4.7 \mathrm{~m}$ ha $(11.6 \%)$, Niger $3.3 \mathrm{~m}$ ha 
(8.14\%) and USA $1.94 \mathrm{~m}$ ha (4.79\%) during 2010-11. But, the lion share in global sorghum production is contributed by USA $(15.7 \%)$ followed by India (12.58\%), Mexico $(12.47 \%)$ and Nigeria (8.59\%). The productivity in developed countries is about five times higher than the productivity in developing countries. The world highest productivity levels were observed in USA $(4520 \mathrm{~kg}$ per ha) while the productivity in India is hovering around $949 \mathrm{~kg}$ per ha.

In India, this crop was one of the major cereal staple during 1950's and occupied an area of more than 18 million hectares but has come down to 7.69 million hectares (TE 2010). Sorghum grain yields in India have average $1170 \mathrm{~kg} / \mathrm{ha}$ in the rainy season and $880 \mathrm{~kg} / \mathrm{ha}$ in the post rainy season in recent years ICRISAT, (2014).

Sorghum is the world's fifth most important cereal after wheat, rice, maize, and barley in both production and area planted (FAO/ICRISAT). Sorghum is one of the main staples for the world's poorest and most foodinsecure people. The crop is generally suited to hot and dry areas where it is difficult to grow other food grains. These are also areas subject to frequent drought. In many of these areas, sorghum is truly a dual-purpose crop; both grain and stover are highly valued outputs. In large parts of the developing world, stover represents up to 50 percent of the total value of the crop, especially in drought years.

Developing countries account for roughly 90 percent of the world's sorghum area and 70 percent of total output (FAO/ICRISAT). Asia and Africa each account for about 25 to 30 percent of global production. Nigeria and Sudan are the major producers in Africa. Production in Africa remains characterized by low productivity and extensive, low-input cultivation. Generally, sorghum is grown primarily for food in the developing countries and in the developed countries almost all sorghum production is used as animal feed.

All India total sorghum production has registered a constant growth rate of $0.10 \%$ per annum during the period 1967-68 to 20102011 which can be mainly attributed to negative production of kharif sorghum rather than positive growth in rabi sorghum production. Though, kharif sorghum yield growth rates were relatively higher, it could not offset the declining growth rates in production, as the growth rates in kharif sorghum area were negative and high. Just opposite is true in case of rabi sorghum where the area decline was not sufficient to undermine the yield growth, thus resulting in positive production growth rates.

Telangana is the twelfth largest state in India in terms of area. Sorghum is an important staple cereal crop grown mostly under rain fed conditions in Telangana. The crop is grown in kharif season in about 1.09 Lakh ha in Telangana with a production of about 1.11 Lakh $\mathrm{mt}$ at an average productivity of about $1015 \mathrm{~kg} / \mathrm{ha}$. (Www.icrisat.in. retrieved on 2014-03-29)

The present study is based on 36years of data i.e., from 1979 to 2015 of Sorghum in Telangana State. The linear growth rate (LGR) and compound growth rate (CGR) for the crop characteristics i.e., area, production and productivity of Sorghum crop in Telangana State are estimated by fitting the following functions, the analysis of the data has been carried out by using data on area production and productivity obtained from web site: www.indian stat.com.

Rao (1965) made an attempt to analyze the trend in agricultural growth in the country as a whole and in different states during the period 1949-50 to 1961-62 to determine the 
major components of agricultural growth. He concluded that the rate of food grains output decreased at the rate $4.4 \%$ in the period $1949-50$ to $1955-56$ to $3.8 \%$ in the period 1955-56 to 1961-62. The growth rate of aggregate crop output remained more or less constant at $4 \%$ despite acceleration in the rate of growth of non food grains from 3.0 to 4.5 $\%$. The growth in productivity was found to be positively correlated with the irrigated area.

Chada (1967) studied the ground nut crop during $1945-50$ to $1964-65$. There was linear growth rates of $4.65,5.23$ and 0.32 in area, production and productivity respectively of groundnut for Punjab state during study period and for total oilseeds, they were 2.93, 3.85 and 0.66 , respectively, at all India level.

Tyagi et al., (1974) attempted to measure the impact of green revolution by estimating linear growth rates for two periods of time between 1950-51 and 1970-71. The estimates of growth rates were suffered from limitations of standardization because he had taken ' $b$ ' as growth rate.

Pavate (1979) made an attempt to study the compound growth rates of area, production and productivity of cotton in during the three decades. During the period of the first two plans increase in area $(3.8 \%)$ rather than increase in yield, which actually fell to -1.1 $\%$. In the next decade, all the three items did not show any significant raise as the growth rates for area, production and productivity were only $-0.2,0.3$ and $0.5 \%$, respectively.

Yoginder Alagh K et al., (1980) aimed at studying the growth rates of crops for the periods of green revolution (period I: 1960-61 to 1969-70) and post-green revolution (period II: $1970-71$ to $1978-79)$. The study revealed that the estimated growth rates in sub-period II were higher than those for sub-period I and that the growth was more evenly spread in sub-period II.

\section{Materials and Methods}

\section{Methodology for the estimation of growth rates}

The study was based on 36 years of data i.e., from 1979-80 to 2015-16. Keeping the objectives in view, linear growth rate (LGR) and compound growth rate (CGR) for the crop characteristics i.e., area, production and productivity of major crops in Telangana State is estimated by fitting the following functions.

\section{Methodology for fitting the trend equations}

The trend equations were fitted by using different growth models. Growth models are nothing but the models that describe the behaviour of a variable overtime. The growth models taken under consideration here are as follows.

\section{Linear function}

A linear model is one in which all the parameters appear linearly.

The mathematical equation is given by

$Y_{t}=a+b t$

Where

$\mathrm{Y}_{\mathrm{t}}$ is the dependent variable i.e., area, production and productivity

$\mathrm{t}$ is the independent variable, time in years $a$ and $b$ are the constants

The constants ' $a$ ' and ' $b$ ' are estimated by applying the Ordinary Leasts Square approach. 


\section{Logarithmic function}

This model shows very rapid growth, followed by slower growth

The mathematical equation is given by

$Y_{t}=a+b \ln (t)$

Where,

$Y_{t}$ is the dependent variable i.e., area, production and productivity

$\mathrm{t}$ is the time in years, independent variable

' $a$ ' and 'b' are constants

The constants ' $a$ ' and ' $b$ ' are estimated by applying the Ordinary Least Squares approach.

\section{Inverse function}

Inverse curve shows a decreasing growth.

Inverse fit is given by the equation

$Y_{t}=a+b / t$

Where,

$\mathrm{Y}_{\mathrm{t}}$ is the dependent variable i.e., area, production and productivity

$t$ is the independent variable, time

' $a$ ' and ' $b$ ' are parameters

The parameters can be estimated by the method of Ordinary Least Squares (OLS).

\section{Quadratic function}

This function is useful when there is a peak or a trough in the data of past periods.
Quadratic fit is given by the equation

$Y_{t}=a+b t+c t^{2}$

Where,

$\mathrm{Y}_{\mathrm{t}}$ is the dependent variable i.e., area, production and productivity

$\mathrm{t}$ is the independent variable, time in years

$\mathrm{a}, \mathrm{b}$ and $\mathrm{c}$ are constants

The constants can be calculated by applying the method of ordinary least squares approach.

\section{Cubic function}

This function is useful when there is or has been, two peaks or two troughs in the data of past periods.

Cubic fit or third degree curve is given by the equation:

$Y_{t}=a+b t+c t^{2}+d t^{3}$

Where,

$\mathrm{Y}_{\mathrm{t}}$ is the dependent variable i.e., area, production and productivity

$\mathrm{t}$ is the independent variable, time in years

$\mathrm{a}, \mathrm{b}, \mathrm{c}$ and $\mathrm{d}$ are parameters

The parameters are calculated by ordinary least squares technique.

\section{Compound function}

This function is useful when it is known that there is or has been, increasing growth or decline in past periods

Compound fit is given by 
$Y_{t}=a b^{t}$ or $\ln Y_{t}=\ln a+t \ln b$

Where,

$\mathrm{Y}_{\mathrm{t}}$ is the dependent variable, area, production and productivity

$\mathrm{t}$ is the independent variable, time in years

$\mathrm{a}$ and $\mathrm{b}$ are parameters or constants

The constants can be obtained by using ordinary least squares technique.

\section{S-curve}

S-curve fit is given by

$Y_{t}=\operatorname{Exp}(a+b / t)$ or $\ln Y_{t}=a+b / t$

Where,

$\mathrm{Y}_{\mathrm{t}}$ is the dependent variable, area, production and productivity

$\mathrm{t}$ is the independent variable, time in years

$\mathrm{a}$ and $\mathrm{b}$ are parameters or constants

Ordinary Least Squares (OLS) method can be applied to estimate the parameters of the model.

\section{Growth function}

The fit is given by

$Y_{t}=\operatorname{Exp}(a+b t)$ or $\ln Y_{t}=a+b t$

Where,

$\mathrm{Y}_{\mathrm{t}}$ is the dependent variable, area, production and productivity

$\mathrm{t}$ is the independent variable, time in years $\mathrm{a}$ and $\mathrm{b}$ are parameters or constants

The constants are obtained by ordinary least squares technique.

\section{Power function}

The fit is given by the equation $\mathrm{Y}_{\mathrm{t}}=\mathrm{at}^{\mathrm{b}}$ or $\ln \mathrm{Y}_{\mathrm{t}}=\ln \mathrm{a}+\mathrm{b} \ln (\mathrm{t})$

Where,

$\mathrm{Y}_{\mathrm{t}}$ is the dependent variable, area, production and productivity

$t$ is the independent variable, time in years $\mathrm{a}$ and $\mathrm{b}$ are parameters or constants

The constants are calculated by ordinary least squares technique.

The fit is similar to exponential fit, but produces a forecast curve that increases or decreases at different rate.

\section{Exponential fit}

If, when the values of $t$ are arranged in an arithmetic series, the corresponding values of $y$ form a geometric series, the relation is of the exponential type.

The function of this type can be given by

$\mathrm{Y}_{\mathrm{t}}=\mathrm{a} \operatorname{Exp}(\mathrm{bt})$ or $\ln \mathrm{Y}_{\mathrm{t}}=\ln \mathrm{a}+(\mathrm{bt})$

Where,

$\mathrm{Y}_{\mathrm{t}}$ is dependent variable i.e., area, production and productivity

$t$ is independent variable, time in years

$\mathrm{a}$ and $\mathrm{b}$ are constants

The constants are calculated by ordinary least squares technique 
Methodology for the estimation of future projections

The future projections of area, production and productivity of major crops in Telangana State up to 2020 AD were estimated upon the best fitted growth model used for fitting the trend equations.

\section{Methodology for the best fitted model}

The choice of the trend equation amongst the available alternatives is very crucial. Many researchers use coefficient of multiple determination, $\mathrm{R}^{2}$ or adjusted $\mathrm{R}^{2}\left(\overline{\mathrm{R}}^{2}\right)$ as the criterion of model selection.

$R^{2}=\frac{\text { EXPLAINEDVARIATION }}{\text { TOTALVARIATION }}=\frac{\sum_{i=1}^{n}\left(\widetilde{Y}_{i}-Y\right)^{2}}{\sum_{i=1}^{n}\left(Y_{i}-\bar{Y}\right)^{2}}$
AdjR $R^{2}=\left(R^{2}\right)=R^{2}-\left[\frac{K-1}{N-K}\right]\left(1-R^{2}\right)$

Where,

$\mathrm{K}$ is the number of constants in the equation $\mathrm{N}$ is the total number of observations

It was observed that $\mathrm{R}^{2}$ is not enough to examine goodness of fit of a model (Reddy, 1978). So in addition to adj $R^{2}$, the residual mean square (RMS) which will also measure the accuracy in forecasting is the best criterion to choose a model from among the alternatives.

Residual mean square $=\frac{\sum\left(\mathrm{y}_{\mathrm{i}}-\hat{\mathrm{y}}_{\mathrm{i}}\right)^{2}}{\text { Residual deg rees of freedom }}$

In the present study, the model with least residual mean square (RMS) and significant adj $\mathrm{R}^{2}$ was considered to be the best fitted model.
Before choosing a model, one should be certain that the disturbance term satisfies all the conditions of randomness, nonautocorrelation, homoscedasticity and normality. In the present study, an attempt has been made to verify the most important assumption of randomness of residuals.

\section{Test for randomness of residuals}

Non-parametric one sample run test can be used to test the randomness of residuals. A run is defined as a succession of identical symbols in which the individual scores or observations originally were obtained. For example, suppose a series of binary events occurred in this order:

$++++--+--++-+-$

This sample of scores begins with a run of four pluses. A run of two minuses follows, then comes another run of one plus and then a run of three minuses and so on. The total runs in the above example are 8 .

If very few runs occur, a time trend or some bunching owing to lack of independence is suggested and if many runs occur, systematic short period cyclical fluctuations seem to be influencing the scores.

Let ' $n_{1}$ ', be the number of elements of one kind and ' $n_{2}$ ' be the number of elements of the other kind in a sequence of $\mathrm{N}=\mathrm{n}_{1}+\mathrm{n}_{2}$ binary events. For small samples i.e., both $\mathrm{n}_{1}$ and $\mathrm{n}_{2}$ are equal to or less than 20 if the number of runs $r$ fall between the critical values, we accept the $\mathrm{H}_{0}$ (null hypothesis) that the sequence of binary events is random otherwise, we reject the $\mathrm{H}_{0}$.

For large samples i.e., if either $\mathrm{n}_{1}$ or $\mathrm{n}_{2}$ is larger than 20, a good approximation to the sampling distribution of $r$ (runs) is the normal distribution, with 
Mean $=\mu_{r}=\frac{2 n_{1} n_{2}}{N}+1$

Standard deviation $=\sigma_{\mathrm{r}}=\sqrt{\frac{2 \mathrm{n}_{1} \mathrm{n}_{2}\left(2 \mathrm{n}_{1} \mathrm{n}_{2}-\mathrm{n}_{1}-\mathrm{n}_{2}\right)}{\left(\mathrm{n}_{1}+\mathrm{n}_{2}\right)^{2}\left(\mathrm{n}_{1}+\mathrm{n}_{2}-1\right)}}$

Then, $\mathrm{H}_{0}$ may be tested by

$$
Z=\frac{r-\mu_{r}}{\sigma_{r}}
$$

The significance of any observed value of $\mathrm{Z}$ computed from the above formula may be determined by reference to the Standard Normal Distribution table.

\section{Results and Discussion}

In Telangana State the average area under Sorghum during the study period (1979-2015) was 678.62 thousand hectares. The coefficient of variation recorded for the study period was 66.37 per cent and the linear and compound growth rates recorded during the study period were -6.04 and -7.7 per cent per annum respectively.

The area of Sorghum in Telangana State exhibited a negative trend and it was found significant at $1 \%$ level of significance in both compound and linear growth rate.

The average production of Sorghum during the study period (1979 to 2015) was 440.48 thousand tones with a coefficient of variation of 53.82 per cent. The linear growth rate and compound growth rate recorded for the study period were -4.6 and -5.5 per cent per annum respectively and these negative growth rates are significant at $1 \%$ level.

Regarding the productivity in Telangana State, the average yield of Sorghum during the study period (1979-80 to 2015-16) was $762.14 \mathrm{~kg} / \mathrm{ha}$, with the coefficient of variation of 27.81 per cent. The linear and compound growth rates during this period were 2.20 and 2.2 per cent respectively.
The productivity of Sorghum had not followed a particular trend during the study period and the linear and compound growth rates were significant at $1 \%$ level of significance.

Growth rates of area, production and productivity of the Sorghum crop for the study period (1979-80 to 2015-16) in Telangana State were shown in the table 1. As a whole, the growth rates of productivity were higher than growth rates of area and production (Fig. 1-4).

\section{Fitting of Different Growth Models}

Area of Sorghum in Telangana State showed a decreasing growth pattern during the study period (from 1979-80 to 2015-16). The results obtained by fitting all the ten growth models were presented in Table 2. The Adj $\mathrm{R}^{2}$ values for all the models were ranging from 0.231 in case of S-curve function to 0.989 in case of Quadratic function, respectively, all the functions have significant Adj $R^{2}$. All functions satisfied the assumption of randomness of residuals.

Cubic function was found to be the best trend equation for the purpose of future projection area as it has exhibited the least RMS, significant $\mathrm{Adj} \mathrm{R}^{2}$ and also satisfied the assumption of randomness of residuals.

The Production of Sorghum in Telangana State showed a decreasing growth pattern during the study period from 1979-80 to 2015-16. The results obtained by fitting all the ten growth models were presented in Table 3. The Adj $R^{2}$ values for all the models were ranging from 0.252 in case of S-curve to 0.889 in case of cubic functions respectively. For almost all the models, Adj $\mathrm{R}^{2}$ values were significant at $1 \%$ level of significance. All the ten functions are satisfied the assumption of randomness of residuals. 
Table.1 Growth Rates in area, production and productivity of sorghum in Telangana State

\begin{tabular}{|c|c|c|c|}
\hline & Area & Production & Productivity \\
\hline Linear & $-6.04 * *$ & $-4.65^{* *}$ & $2.20^{* *}$ \\
\hline Compound & $-7.7 * *$ & $-5.5^{* *}$ & $2.2 * *$ \\
\hline C.V (\%) & 66.37 & 53.82 & 27.81 \\
\hline$* *$ Significance at $1 \%$ level & \multicolumn{3}{|c}{ * Significance at 5\% level } \\
\hline
\end{tabular}

Table.2 Average area, production and productivity of sorghum in Telangana State

\begin{tabular}{|l|c|}
\hline Items & Telangana State \\
\hline Area('000ha) & 678.93 \\
\hline Production('000 tonnes) & 440.47 \\
\hline Productivity(kg/ha) & 769 \\
\hline
\end{tabular}

Table.3 Linear and compound growth rates of area, production and productivity of sorghum in Telangana State

\begin{tabular}{|l|c|c|c|}
\hline ZONES & Area & Production & Productivity \\
\hline Linear growth rate & $-6.04^{* *}$ & $-4.65^{* *}$ & $2.20^{* *}$ \\
\hline Compound growth rate & $-7.7^{* *}$ & $-5.5^{* *}$ & $2.2^{* *}$ \\
\hline
\end{tabular}

** Significant at $1 \%$ level

Table.4 Growth models for the area, production and productivity of sorghum in Telangana State

\begin{tabular}{|c|c|c|c|c|c|c|c|c|c|c|}
\hline \multicolumn{11}{|c|}{ Area } \\
\hline Model & Linear & Logarithmic & Inverse & Quadratic & Cubic & Compound & Power & S-Curve & Growth & Exponential \\
\hline $\operatorname{Adj} R^{2}$ & $0.971 * *$ & $0.889 * *$ & $0.424 * *$ & $0.989 * *$ & $0.988 * *$ & $0.934 * *$ & $0.659 * *$ & $0.231 * *$ & $0.934 * *$ & $0.934 * *$ \\
\hline RMS & 5835.8 & 22525.99 & 116871 & 2228.08 & 2224.9 & 28709.23 & 409791 & 28470.8 & 375465 & 28447.54 \\
\hline Runs & 8 & 3 & 3 & 10 & 10 & 5 & 3 & 7 & 3 & 7 \\
\hline \multicolumn{11}{|c|}{ Production } \\
\hline $\operatorname{Adj} R^{2}$ & $0.647 * *$ & $0.538^{* *}$ & $0.304 * *$ & $0.66^{* *}$ & $0.692 * *$ & $0.638^{* *}$ & $0.425^{* *}$ & $0.169 * *$ & $0.638^{* *}$ & $0.638^{* *}$ \\
\hline RMS & 7125.6 & 9915.55 & 29281.2 & 6942.69 & 5896.4 & 9981.6 & 65919 & 10055.9 & 41685 & 10058.39 \\
\hline Runs & 19 & 15 & 7 & 14 & 19 & 14 & 5 & 12 & 9 & 11 \\
\hline \multicolumn{11}{|c|}{ Productivity } \\
\hline $\operatorname{Adj} \mathbf{R}^{2}$ & $0.729 * *$ & $0.465^{* *}$ & $0.097 *$ & $0.749 * *$ & $0.786 * *$ & $0.703 * *$ & $0.454 * *$ & $0.088^{*}$ & $0.703^{* *}$ & $0.703^{* *}$ \\
\hline RMS & 12175 & 24064.52 & 40597.2 & 10940.72 & 9093.5 & 11634.24 & 40370 & 11622 & 21329 & 11479.65 \\
\hline Runs & 16 & 9 & 5 & 18 & 20 & 18 & 7 & 16 & 9 & 18 \\
\hline
\end{tabular}

Table.5 Projections of area, production and productivity sorghum in Telangana State

\begin{tabular}{|l|c|c|c|}
\hline Year & Area('000 ha) & Production (' 000 tonnes) & Productivity(kg/ha) \\
\hline $\mathbf{2 0 1 6 - 2 0 1 7}$ & 12 & 50.79 & 1081.565 \\
\hline $\mathbf{2 0 1 7 - 2 0 1 8}$ & 11 & 44.69 & 1105.54 \\
\hline $\mathbf{2 0 1 8 - 2 0 1 9}$ & 9 & 25.05 & 1131.124 \\
\hline $\mathbf{2 0 1 9 - 2 0 2 0}$ & 5 & 6.19 & 1155.95 \\
\hline $\mathbf{2 0 2 0 - 2 0 2 1}$ & 1 & 2.61 & 1180.011 \\
\hline
\end{tabular}


Fig.1 Area, production and productivity of sorghum in Telangana State

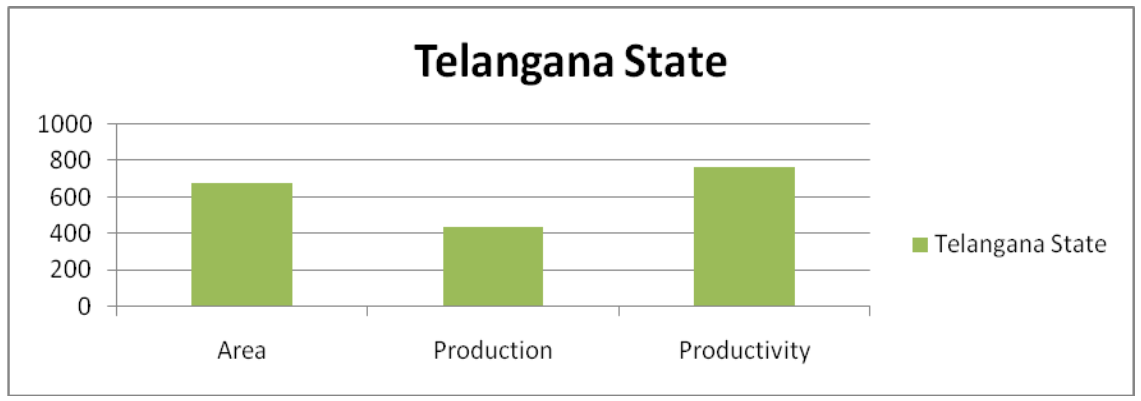

Fig.2 Trend of sorghum area in Telangana State

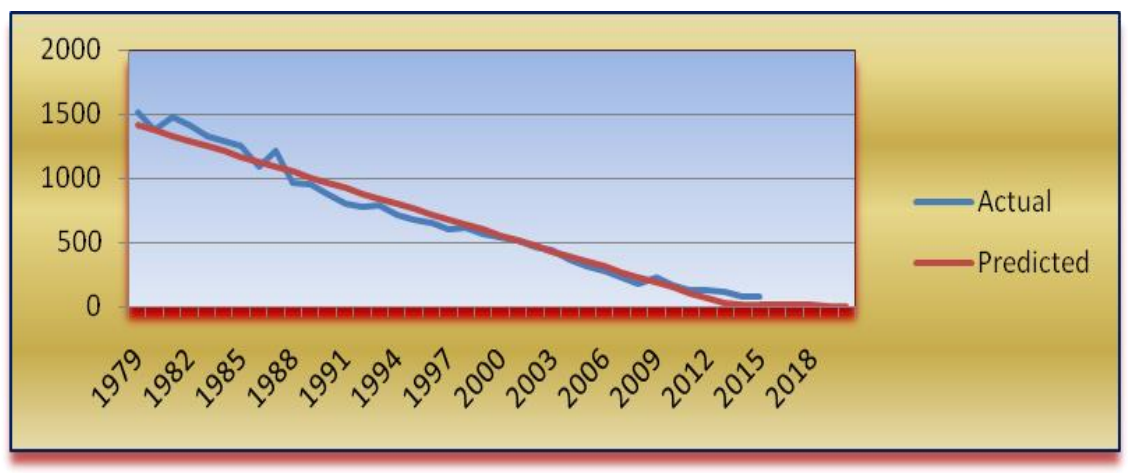

Fig.3 Trend of sorghum production in Telangana State

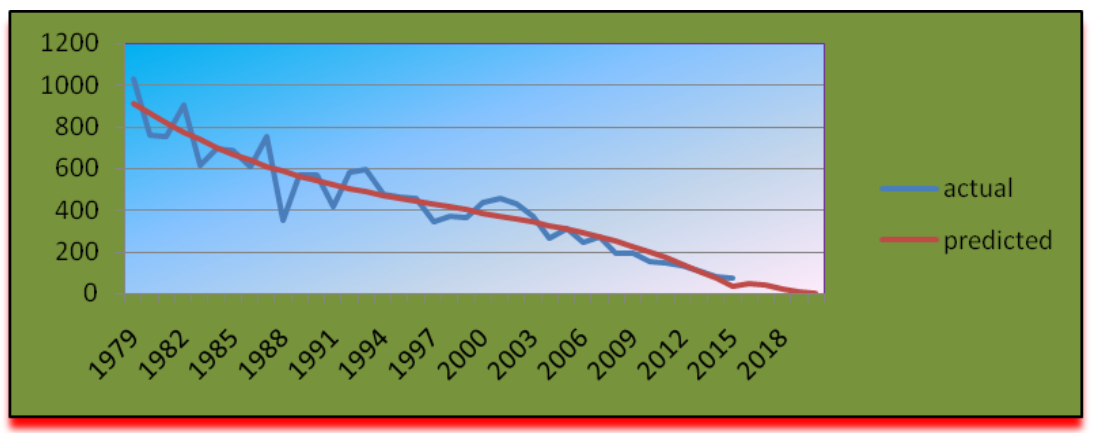

Fig.4 Trend of sorghum productivity in Telangana State

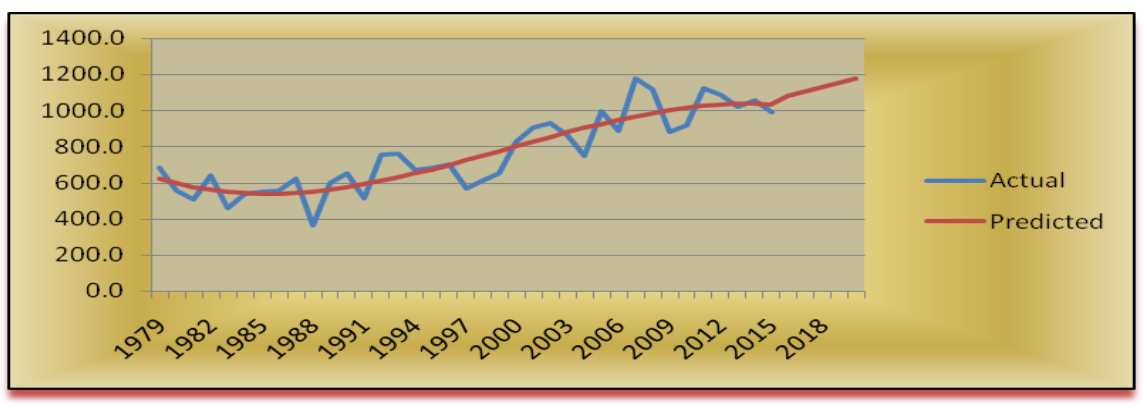


Quadratic function was found to be the best trend equation for the purpose of future projection of production as it has exhibited the least RMS and significant $\operatorname{Adj}^{2}$ and also satisfied the assumption of randomness of residuals.

The Productivity of Sorghum in Telangana State had not shown any particular trend pattern during the study period. The results obtained by fitting all the ten growth models were presented in Table 4 . The Adj $\mathrm{R}^{2}$ values for all the models were ranging between 0.088 in case of S-curve and 0.786 in case of cubic function respectively. For almost all the models, Adj $\mathrm{R}^{2}$ values were significant at $1 \%$ level of significance. But, for inverse, and scurve models Adj $R^{2}$ values were significant at 5\% level of significance and satisfied the test of randomness of residuals.

Cubic function was found to be the best trend equation for future projection purpose of productivity, further it has exhibited the least RMS and significant Adj $\mathrm{R}^{2}$ and also satisfied the assumption of randomness of residuals.

\section{Future Projections of Area, Production and Productivity up to $2020 \mathrm{AD}$}

The future projections of area, production and productivity of Sorghum in Telangana State by $2020 \mathrm{AD}$ were calculated and the results were presented in the Table 5 .

Area under Sorghum in Telangana State was projected by using linear function which was found to be best for this purpose as it has the least RMS and significant Adj $R^{2}$ and also fulfilled the assumption of randomness of residuals. The area under Sorghum projected by linear function by $2020 \mathrm{AD}$ would be 1 thousand hectares which as in decreasing trend.

Regarding the production of Sorghum, cubic function was found to be the best model for future projections by $2020 \mathrm{AD}$ as it has the least residual mean square, significant Adj $\mathrm{R}^{2}$ and also satisfied the assumption of randomness of residuals. The projected production would be decreasing at 2.61 thousand tonnes by $2020 \mathrm{AD}$.

Regarding the productivity of Sorghum, cubic function was found to be the best model for future projections by $2020 \mathrm{AD}$ as it has the least residual mean square, significant Adj $\mathrm{R}^{2}$ and also satisfied the assumption of randomness of residuals. The projected productivity would be increasing at 1180.011 $\mathrm{kg} / \mathrm{ha}$ by $2020 \mathrm{AD}$.

In conclusions, in telangana state the area and production is drastically decreased and going to very near to zero and even the Statistical future projections are indicating negative which is impossible but there would be very negative in coming future. The policy makers must have emphasis on increasing the area of Sorghum in Telangana, as this crops is drought resistant and it can be grown with minimum rain fall. Further itcan be used for food and fodder. The policy makers must encourage the Sorghum cultivating farmers by giving subsidies on seeds, fertilizers and seasonal alternative MSP to increase the area and production.

\section{References}

Chatterji, A. 1966. A study of agricultural rates during 1950-60 in India. Indian Journal of Agricultural Economics. 20: 20-32

Pavate, M.V. 1979. Progress of cotton in three decades of study of growth rates. Agriculture Situation in India. 24: 289294.

Rao, C.H.H. 1965. Agricultural growth and stagnation in India. Economic and Political Weekly. 17: 407-411.

Tyagi, B.N., Dubey, R.C. and Sagar, V. 1974. Study of growth rates of area, 
production and productivity of groundnut crop in Uttar Pradesh for the period from 1960-61 to 1971-72. Agricultural Situation in India. 29: 391396.

Yoginder Alagh, K and Sharma, P.S. 1980.
Growth rates of crop production 196061 to $1978-79$ is it decelerating? Indian Journal of Agricultural Economics. 35 (2): 104-118.

\section{How to cite this article:}

Srinivas, R. and Srinivasa Chary, D. 2020. Growth Rates, Growth Models and Future Projections of Sorghum in Telangana State. Int.J.Curr.Microbiol.App.Sci. 9(12): 2514-2524. doi: https://doi.org/10.20546/ijcmas.2020.912.299 